\title{
Originals
}

\section{Effect of vanadate administration on blood glucose and insulin levels as well as on the exocrine pancreatic function in streptozotocin-diabetic rats}

\author{
M. Bendayan and D. Gingras \\ Department of Anatomy, Faculty of Medicine, Universite de Montreal, Montreal, Quebec, Canada
}

\begin{abstract}
Summary. In the present study, streptozotocin-induced diabetic rats with their corresponding controls, were treated orally with sodium metavanadate. A gradual increase of the vanadate concentration up to $0.8 \mathrm{mg} / \mathrm{ml}$ in the drinking water, lowered the blood glucose levels of the diabetic animals to normal values without changing the insulin levels. On the other hand, vanadate did not affect the blood glucose levels of the non-diabetic animals; it did however induce lower levels of circulating insulin in these animals. The lowering of the glycaemic values of the diabetic animals was closely related to the consumption of vanadate. When the treatment was ceased, the blood glucose levels rose rapidly. The diabetic animals responded to the vanadate treatment with two sensitivities; while the large majority of the diabetic animals displayed stable normoglycaemic values, others had fluctuating values. Amylase content in the exocrine pancreas of these two subgroups of animals was studied separately and compared to
\end{abstract}

that from the non-treated control and diabetic animals. The presence of amylase in the pancreatic acinar cells was assessed by the protein A-gold immunocytochemical approach and biochemical determinations. Amylase was found to be very low in the non-treated diabetic animals. Lowering of the blood glucose levels induced by the vanadate treatment restored the amylase to levels similar to those of the controls. However, vanadate-treated diabetic animals with fluctuating levels of blood glucose, demonstrated only a partial recovery of amylase. Thus, vanadate treatment was found to have a normalizing effect on blood glucose levels in diabetic animals as well as restoring amylase content in the pancreas of diabetic animals. This appeared to be closely related to the glycaemic values of the diabetic animals.

Key words: Diabetes mellitus, vanadate, pancreas, amylase, streptozotocin.
Recent studies have demonstrated that oral administration of sodium vanadate to diabetic rats normalizes their blood glucose levels [1-3]. This appears to be due to the insulin-mimetic effect vanadate exerts on various target tissues, via a post-receptor mechanism. Many studies are currently being performed in order to elucidate the mechanism by which vanadate is involved in the cellular regulation of glucose metabolism, stimulation of glucose uptake, oxidation and glucose incorporation into lipids in adipocytes [5-7] and the increase in hepatic glycogenesis $[1,8]$. Vanadate has also been shown to stimulate DNA synthesis [9] and to prevent the decline in cardiac performance due to diabetes [2]. Furthermore, a recent study on the action of vanadate indicates an insulinotropic effect also [10]. This study was, however, performed in vitro using isolated pancratic islets.

Endocrine and exocrine pancreatic tissues are closely interrelated both structurally and functionally, in normal as well as in pathological conditions [11-15]. Previous studies have established that the pancreatic exocrine function and secretion of amylase in particu- lar, are drastically altered in diabetes [14-17]. Indeed, streptozotocin-diabetic [14-17], as well as spontaneous diabetic [18], rats show a major decrease in amylase secretion. Along with this decrease, we have found that secretion of chymotrypsinogen and lipase are enhanced $[15,19]$. These changes in exocrine function of the pancreas which occur in diabetic conditions are totally restored by daily administration of insulin [15, 17, 19]. However, it is difficult from these studies to discriminate between the direct action which insulin and/or glucose levels may have on acinar cells.

In the present study, we have evaluated the effect of vanadate on blood glucose and insulin levels in control and diabetic animals. In addition, the secretion of amylase by pancreatic acinar cells was investigated after the normalization of blood glucose levels of streptozotocindiabetic animals by the oral administration of sodium vanadate. The results obtained tend to demonstrate that vanadate lowers blood glucose levels without raising those of circulating insulin, and that amylase content in pancreatic acinar cells is closely related to the blood glucose level. 


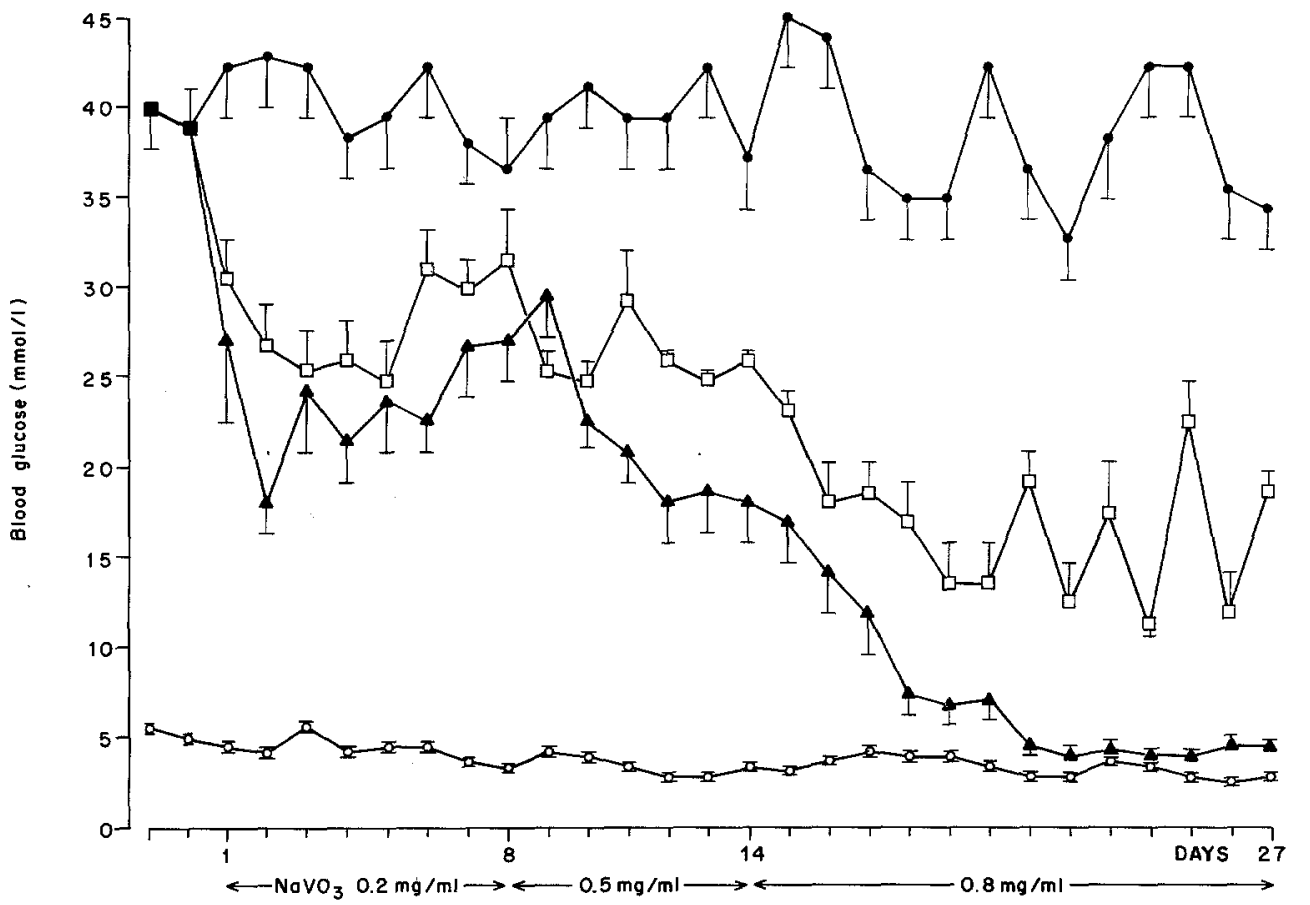

Fig. 1. Effect of oral administration of vanadate $\left(\mathrm{Na} \mathrm{VO}_{3}\right)$ on blood glucose levels of various groups of animals. (O) Group II control animals receiving the vanadate solution; ( $\Delta$ ) Group IV streptozotocin-diabetic animals receiving the vanadate solution and maintaining a stable normoglycaemic state by the third and fourth week of treatment; () Group IV streptozotocindiabetic animals receiving the vanadate solution but demonstrating fluctuating glycaemic values; (๑) Group III streptozotocindiabetic animals maintained on water. Mean values \pm SEM

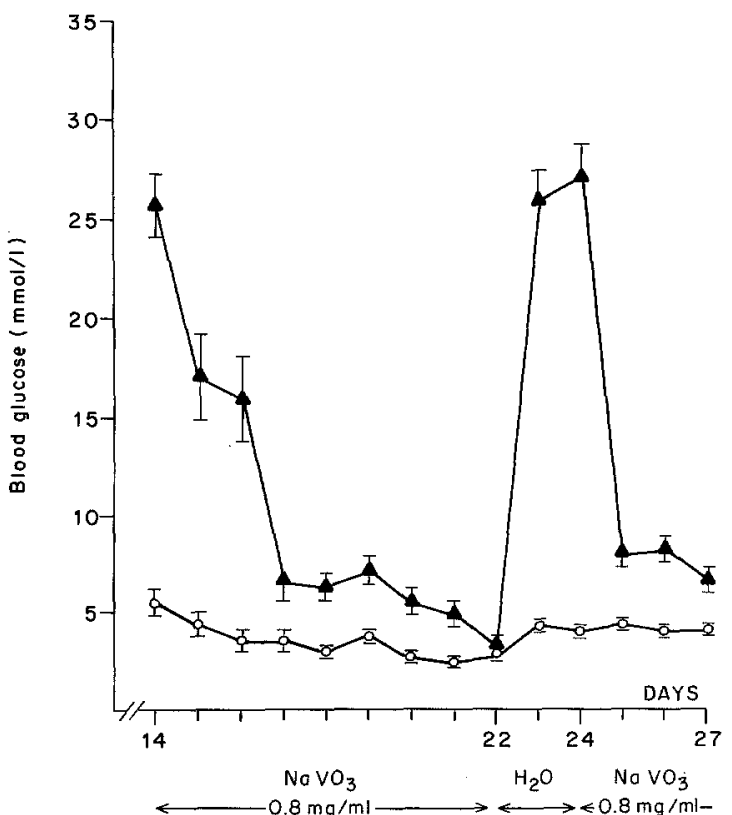

ig. 2. Effect of the replacement of the vanadate $\left(\mathrm{NaVO} \mathrm{VO}_{3}\right)$ treatment $y$ tap water $\left(\mathrm{H}_{2} \mathrm{O}\right)$ on blood glucose level of vanadate-treated strepzotocin-diabetic (A) and vanadate-treated control (O) animals. lean values \pm SEM

\section{Iaterials and methods}

hronic hyperglycaemia was induced in $100 \mathrm{~g}$ Sprague Dawley male its by streptozotocin administration $(75 \mathrm{mg} / \mathrm{kg}$ body weight in $7 \mathrm{mmol} / 1$ sodium citrate buffer $\mathrm{pH} 4.5$ ). Control animals received le sodium citrate alone. The animals were kept in individual cages nd had free access to food and water. The streptozotocin-diabetic nimals demonstrated strong glucosuria (reagent strips, N-Multistix, Iiles, Ames Division, Ontario, Canada), 24 to $48 \mathrm{~h}$ after the streptotocin administration. They also exhibited strong ketonuria and prosinuria with the urine $\mathrm{pH}=5$. Blood samples, obtained daily from the til vein, were analysed for glucose levels using Dextrostix reagent rips with a Glucometer (Miles). Blood glucose levels averaged
$30.6 \pm 2.7 \mathrm{mmol} / 1$ for the non-fasted streptozotocin-diabetic animals, vs $4.8 \pm 0.4$ for the controls $(p<0.0001)$. Insulin levels were determined by radioimmunoassay using a goat anti-guinea pig insulin antibody and porcine insulin as a standard (insulin RIA Kit, Chromacod, BIOMEGA, Montreal, Canada). They averaged $26.50 \pm 1.2 \mathrm{mU} / \mathrm{I}$ for the streptozotocin-diabetic animals vs $45.00 \pm 3.00 \mathrm{mU} / 1$ for the controls. Levels of insulin were thus significantly low when compared to controls $(p<0.001)$. Because of the remaining circulating insulin, the animals survived easily without treatment with exogenous insulin.

One week after the onset of the hyperglycaemic state, the animals were divided into four different groups according to the drinking solution they were given.

Group I, consisted of normoglycaemic control animals $(n=5)$ kept on tap water.

Group II, consisted of normoglycaemic control animals $(n=10)$ given a solution of sodium chloride and sodium metavanadate.

Group III, consisted of hyperglycaemic streptozotocin-diabetic animals $(n=5)$ kept on tap water.

Group IV, consisted of hyperglycaemic streptozotocin-diabetic animals $(n=35)$ given a solution of sodium chloride and sodium metavanadate.

The sodium chloride was given at a constant concentration of $80 \mathrm{mmol} / \mathrm{l}$, while the sodium metavanadate was given at increasing concentrations. During the first week of the experiment, the animals drank a solution of $0.2 \mathrm{mg} / \mathrm{ml}$ of sodium metavanadate; this was followed by $0.5 \mathrm{mg} / \mathrm{ml}$ during the second week and $0.8 \mathrm{mg} / \mathrm{ml}$ during the third and fourth week (Fig.1). The vanadate solutions were prepared freshly every two days. All animals had free access to food (Purina Chow, Country Foods, Syracuse, NY, USA).

In a pilot experiment performed at the beginning of the study, four diabetic and four control animals were given directly a vanadate solution of $0.8 \mathrm{mg} / \mathrm{ml}$. The animals rapidly showed signs of suffering and two of them died. Thus, we opted for a protocol in which the concentration of vanadate was increased gradually.

Blood glucose levels were analysed daily on samples obtained from the tail vein. Periodically, we also tested blood glucose and insulin levels after $12 \mathrm{~h}$ of fasting. On one occasion, four animals from Group IV having reached low glucose levels, and four animals from Group II were selected and the vanadate solution was replaced by tap water for a period of two days. The animals were returned to the vanadate solution $(0.8 \mathrm{mg} / \mathrm{ml})$ after these two days.

At the end of the experiments, the animals were killed by decapitation and blood samples were collected for determination of various 

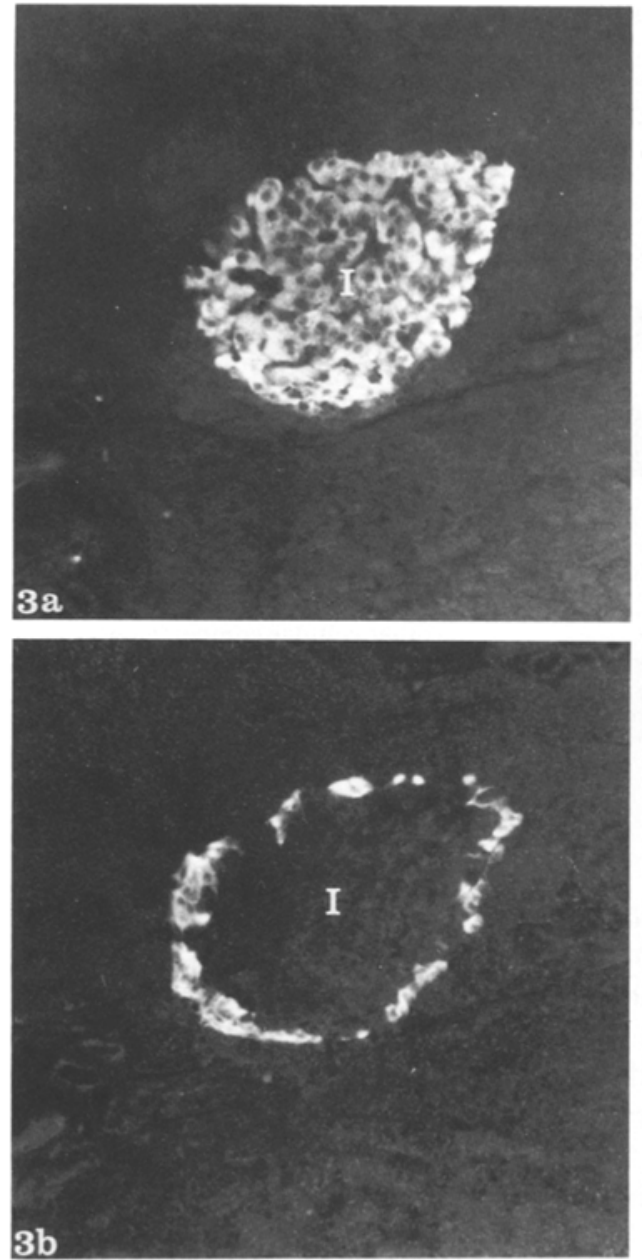
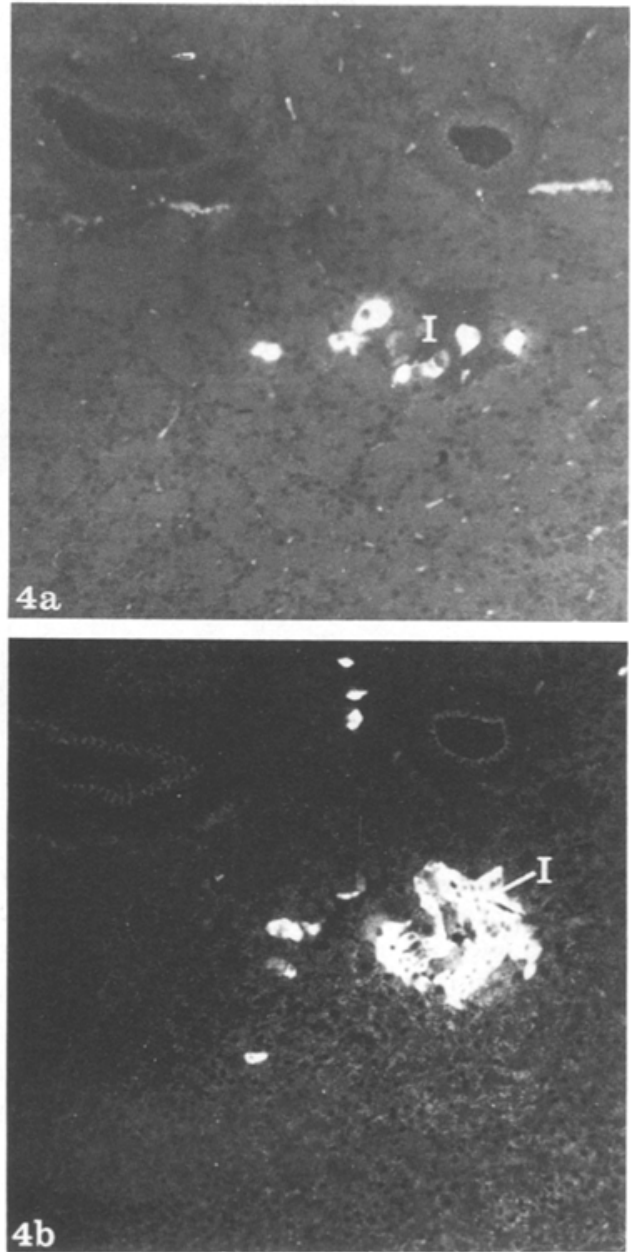

Fig.3. Immunofluorescence demonstrating insulin (a) and glucagon (b) containing cells in pancreatic tissue of a vanadate-treated control animal. The insulin containing cells are numerous and formed the core of the islet of Langerhans ( $I$ ), while the glucagon containing cells constitute a shell at the periphery of the islet. $\times 228$

Fig.4. Immunofluorescence demonstrating insulin (a) and glucagon (b) containing cells in pancreatic tissue of a vanadate-treated diabetic animal. The insulin containing cells are few in number while the glucagon containing cells are more numerous and occupy the major part of the islet of Langerhans (I). $\times 228$ parameters, in particular blood glucose and insulin levels were determined using the glucose oxidase method (ERA-2001, Beckman Instruments, Palo Alto, Calif, USA) and radioimmunoassay respectively.

In order to avoid variations due to feeding and circadian influences, daily blood sampling was always performed at the same time (10.00 hours). The animals were also killed at this time of the day, schedules were planned to take these factors into consideration. Food consumption did not seem to differ among the animals. Fluid intake however, did vary among the groups. Indeed, the non-treated hyperglycaemic animals drank an average of $150 \pm 30 \mathrm{ml} \cdot 100 \mathrm{~g}^{-1} \cdot$ day $^{-1}$ vs $50 \pm 8 \mathrm{ml} \cdot 100 \mathrm{~g}^{-1} \cdot$ day $^{-1}$ for the non-treated normoglycaemic animals $(p<0.001)$. However, the vanadate-treated diabetic animals drank $20 \pm 5 \mathrm{ml} \cdot 100^{-1} \cdot$ day $^{-1}$ and the vanadate-treated control animals $15 \pm 5 \mathrm{ml} \cdot 100^{-1} \cdot$ day $^{-1}$.

\section{Immunocytochemistry}

For light microscopy immunocytochemistry, a fragment of the splenic part of the pancreas was fixed by immersion in Bouin's fixative and embedded in paraffin according to standard techniques. $5 \mu \mathrm{m}$ thick sections were mounted on glass slides and rehydrated through decreasing concentrations of ethanol. After washing in phosphate buffered saline (PBS) $0.01 \mathrm{~mol} / \mathrm{l}$, the sections were incubated with the specific antibody, either an anti-insulin or an anti-glucagon (Miles Laboratory, Elkhart, Ind, USA) at $1 / 200$ and $1 / 50$ dilution in PBS respectively, for $2 \mathrm{~h}$ at room temperature followed by an incubation with fluorescein-labelled anti-rabbit or anti-guinea-pig immunoglobulin antibodies (Miles Laboratory) for $60 \mathrm{~min}$ at room temperature [14]. The sections were counterstained with Evan's blue prior to exam- ination with a Leitz orthoplan microscope using a Ploemopak illuminator (Wild Leitz, Montreal, Canada) with the appropriate filter for fluorescein. Serial sections were systematically used.

For the electron microscopy immunocytochemical study, small fragments of the splenic part of the pancreas were fixed by immersion with $0.1 \mathrm{~mol} / 1$ phosphate buffered $1 \%$ glutaraldehyde for $2 \mathrm{~h}$ at room temperature and then washed in the same buffer. The tissues were postfixed with phosphate buffered $1 \%$ osmium tetroxide for $60 \mathrm{~min}$ at $4^{\circ} \mathrm{C}$. Embedding was performed in Epon according to standard procedures. Thin sections were cut, mounted on nickel grids and processed for immunocytochemistry. Amylase antigenic sites were revealed at the electron microscope level by applying a specific

Table 1. Blood glucose and insulin levels in the different groups of animals

\begin{tabular}{llrl}
\hline Groups & $\begin{array}{l}\text { Glucose } \\
\mathrm{mmol} / 1\end{array}$ & $\begin{array}{l}\text { Insulin } \\
\mathrm{mU} / 1\end{array}$ \\
\hline I & Control $\left(\mathrm{H}_{2} \mathrm{O}\right)$ & $3.6 \pm 0.1$ & $44.78 \pm 2.89$ \\
II & Control + vanadate & $3.5 \pm 0.3$ & $28.10 \pm 1.88$ \\
III & Streptozotocin $\left(\mathrm{H}_{2} \mathrm{O}\right)$ & $33.8 \pm 2.2$ & $21.54 \pm 0.86$ \\
IV & Streptozotocin + vanadate & $4.4 \pm 0.2$ & $16.82 \pm 1.20$ \\
IV $^{\mathrm{b}}$ & Streptozotocin + vanadate & $18.3 \pm 1.1$ & $14.98 \pm 1.55$ \\
\hline
\end{tabular}

${ }^{a}$ subgroup with a stable response to vanadate ${ }^{b}$ subgroup with an unstable response to vanadate; Mean values \pm SEM.

Student's $t$ test, paired experiments performed between values in each column: (glucose column: I vs II NS; I vs III $p<0.0001$; I vs IV $^{b}$ $p<0.001 ;$ I vs IV $\left.{ }^{\mathrm{a}}, p<0.01\right)$

(insulin column: I vs II $p<0.001$; I vs III $p<0.001$; I vs IV $p<0.0001 ;$ IV $^{\mathrm{a}}$ vs IV $\mathrm{V}^{\mathrm{b}} \mathrm{NS}$; III vs IV $\mathrm{IV}^{\mathrm{a}} p<0.001$ ) 

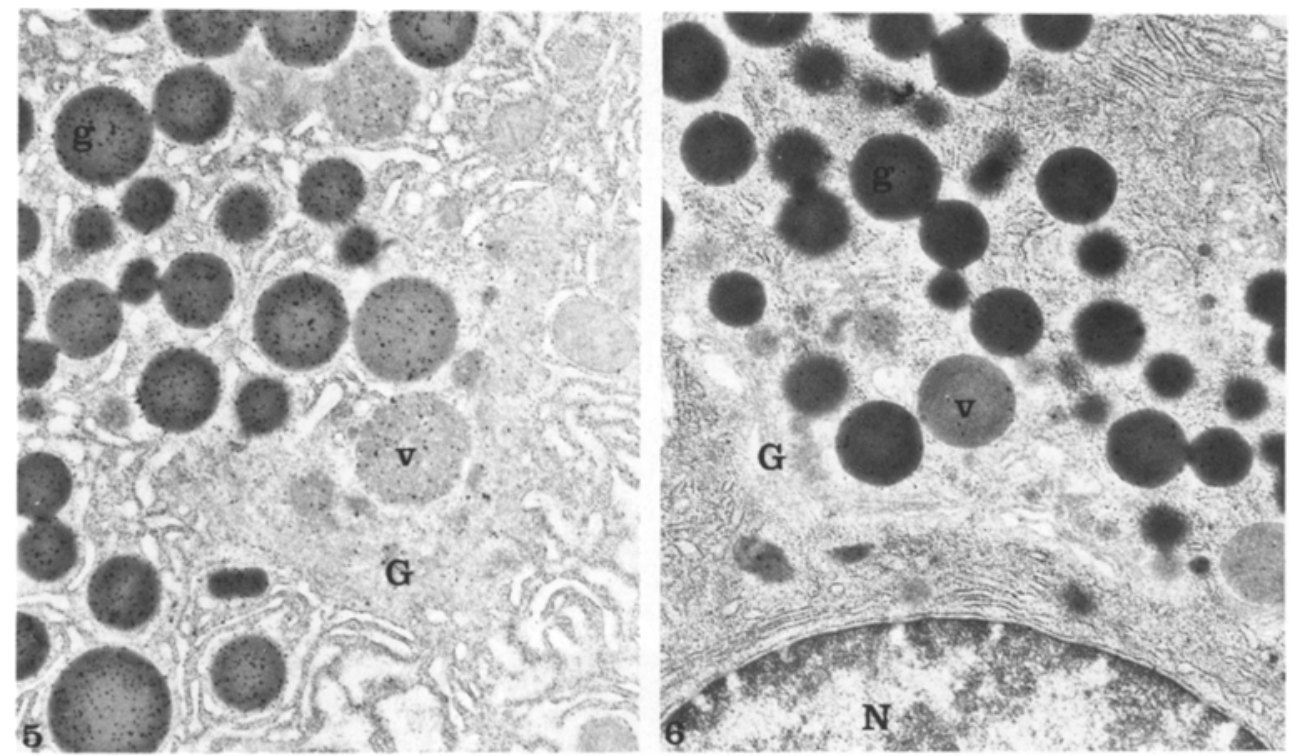

Fig.5. Electron micrograph of an acinar cell of a non-treated control animal (Group I). Protein A-gold immunocytochemistry for amylase demonstrating intense labelling. The gold particles revealing amylase antigenic sites are present over the Golgi apparatus $(G)$, the condensing vacuoles $(v)$ and the secretory zymogen granules ( $g$ ). $\times 15000$

Fig. 6. Electron micrograph of an acinar cell from a non-treated diabetic animal (Group II). Immunocytochemistry for amylase demonstrating low labelling. Few gold particles are present over the secretory zymogen granules (g). The other cellular compartments are almost devoid of labelling. $G$, Golgi apparatus; $v$, condensing vacuole; $N$, nucleus. $\times 19000$

anti-amylase antibody [20] and the protein A-gold immunocytochemical technique as described in detail previously [21]. The specificity of the labelling obtained was assessed through various control experiments as reported previously [21]. The results obtained were evaluated through quantitative determinations of labelling intensity, according to methods described previously $[15,21]$. Twenty-four micrographs of different acinar cells, located in the tele-insular region of the pancreas, were recorded for each animal at an original magnification of $\times 7000$. The density of labelling was evaluated at a final magnification of $\times 42000$ using a MOP-3 Carl Zeiss image analysis system.

\section{Biochemistry}

For the biochemical determination of amylase, the tissue fragments were immersed in the appropriate Triton buffer [22] and homogenized. Amylase was analysed according to the procedures described by Ceska [23] using the Phadebas reagents (Pharmacia, Montreal, Canada), while total protein content was determined by the Lowry method [24].

\section{Statistical analysis}

Statistical evaluations of the morphometrical and biochemical results were performed by paired experiments using the Student's $t$-test.

Table 2. Immunocytochemical and biochemical determinations of amylase in pancreatic tissue of the different groups of animals

\begin{tabular}{llcc}
\hline Groups & $\begin{array}{l}\text { Immunocyto- } \\
\text { chemistry } \\
\text { particles } / \mu \mathrm{m}^{2}\end{array}$ & $\begin{array}{l}\text { Biochemistry } \\
\mathrm{U} / \mathrm{mg} \\
\text { proteins }\end{array}$ \\
\hline I & Control $\left(\mathrm{H}_{2} \mathrm{O}\right)$ & $102.5 \pm 1.2$ & $756 \pm 78$ \\
II & Control + vanadate & $106.7 \pm 13.1$ & $706 \pm 127$ \\
III & Streptozotocin $\left(\mathrm{H}_{2} \mathrm{O}\right)$ & $13.4 \pm 4.1$ & $4 \pm 2$ \\
IV & Streptozotocin + vanadate & $103.2 \pm 11.5$ & $796 \pm 300$ \\
IV $^{\mathrm{b}}$ & Streptozotocin + vanadate & $62.8 \pm 8.2$ & $325 \pm 96$ \\
\hline
\end{tabular}

${ }^{a}$ subgroup with a stable response to vanadate, ${ }^{b}$ subgroup with an unstable response to vanadate; Mean values \pm SEM

Student's $t$ test, paired experiments performed between values in each column: (immunocytochemistry: I vs II NS; I vs IV ${ }^{a}$ NS; I vs III $p<0.0001 ; \mathrm{I}$ vs $\left.\mathrm{IV}^{\mathrm{b}} p<0.001\right)$

(biochemistry: I vs II NS; I vs IV NS; I vs III $p<0.0001$; I vs IV ${ }^{b}$ $p<0.001)$

\section{Results}

Vanadate treatment reduced the level of hyperglycaemia in streptozotocin-diabetic rats, while having little effect on non-diabetic control animals. Indeed, daily analysis of the blood glucose revealed that the vanadate-treated diabetic rats (Group IV) responded to the treatment by lowering their blood glucose levels (Fig.1, Table 1). The animals responded to the treatment by maintaining low glucose levels for several days, only when the concentration of the vanadate reached $0.8 \mathrm{mg} / \mathrm{ml}$. The pilot experiment performed at the beginning of the study, showed that immediate exposure to high concentrations of vanadate was not appropriate. It was only through a progressive increase in the amounts of vanadate, that the animals were able to sustain the treatment. The animals responded to the treatment with two different sensitivities. While the majority of the animals $(n=26)$ became normoglycaemic and maintained a stable level of glycaemia $(<5.5 \mathrm{mmol} / \mathrm{l})$ by the third week as soon as the levels of vanadate in their drinking water reached $0.8 \mathrm{mg} / \mathrm{ml}$, other animals $(n=6)$ showed variable levels of glycaemia which fluctuated between 10 and $16 \mathrm{mmol} / \mathrm{l}$, even when the vanadate concentration was at $0.8 \mathrm{mg} / \mathrm{ml}$ (Fig.1). These animals were studied separately forming two subgroups of Group IV. When levels of vanadate were lower, at $0.2 \mathrm{mg} / \mathrm{ml}$ or $0.5 \mathrm{mg} / \mathrm{ml}$, blood glucose levels of the vanadate-treated diabetic animals initially decreased but returned rapidly to high levels (Fig.1). On the other hand, non-treated streptozotocin-diabetic animals (Group III) remained hyperglycaemic throughout the experiment (Fig.1). Normoglycaemic control animals (Group II) drinking the vanadate solution at the same concentrations and for the same time periods as the diabetic ones, had glucose levels not significantly different from those of the control animals drinking tap water (Fig.1, Table 1). The 

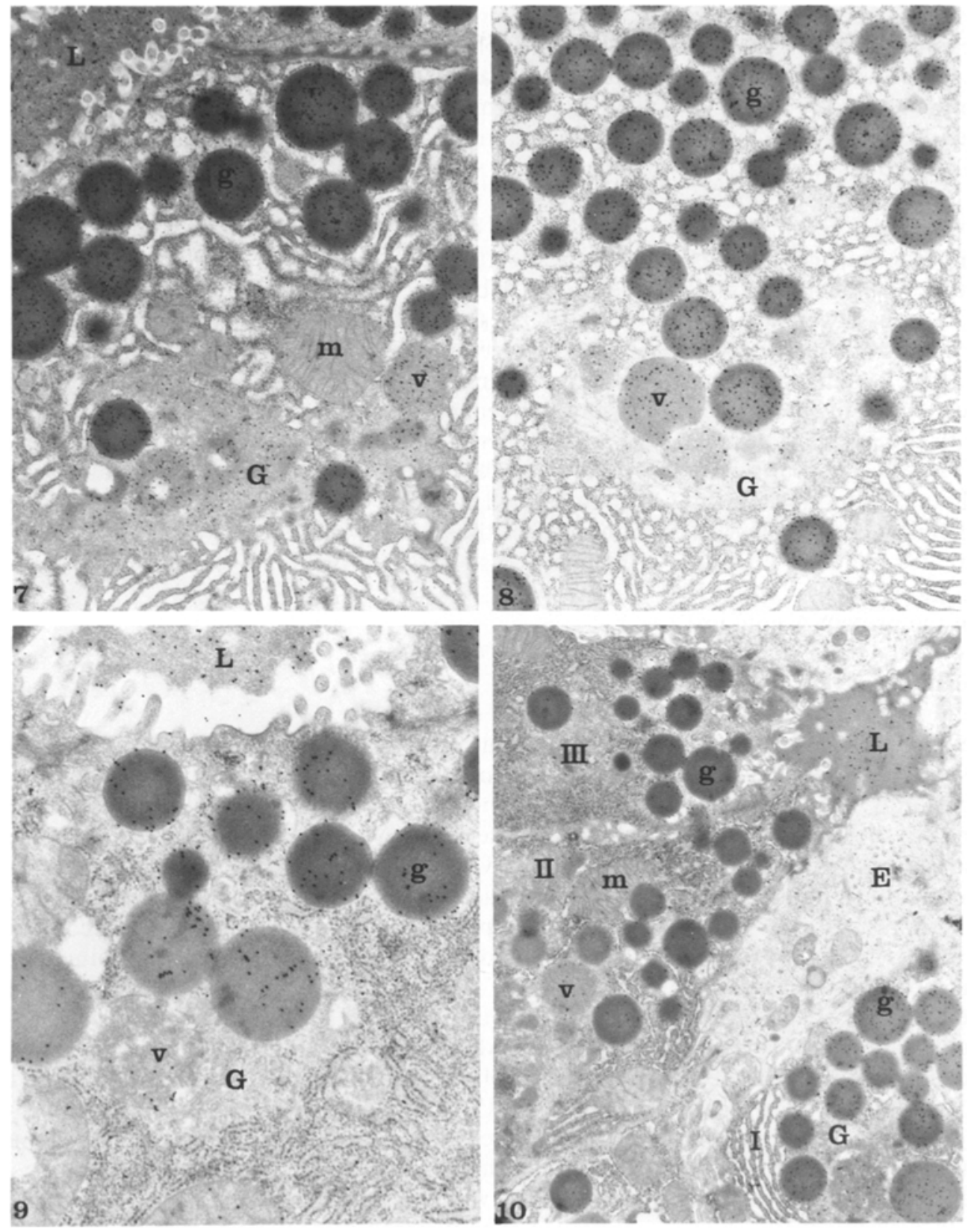

Fig.7. Electron micrograph of an acinar cell from a vanadate-treated control animal (Group III). Immunocytochemistry for amylase demonstrating intense labelling. The gold particles are present over the rough endoplasmic reticulum, the Golgi apparatus $(G)$, the condensing vacuoles $(v)$ and the secretory zymogen granules $(\mathrm{g})$. Labelling is also present over the content of the acinar lumen $(L)$. Mitochondria $(m)$ are devoid of labelling. $\times 19000$

Fig.8. Electron micrograph of an acinar cell from a vanadate-treated diabetic animal with stable normoglycaemia (Group IV, first subgroup). Immunocytochemistry for amylase demonstrating intense la belling. The gold particles are present over the rough endoplasmic reticulum, the Golgi apparatus $(G)$, the condensing vacuoles ( $v$ ) and the secretory zymogen granules $(g)$. $\times 19000$

Figs. 9 and 10 . Electron micrographs of acinar cells from vanadate-treated diabetic animals with unstable glycaemia (Group IV, second subgroup). Immunocytochemistry for amylase demonstrating moderate and variable labellings. Many cells show a labelling by gold particles over the Golgi apparatus $(G)$, condensing vacuoles (v) and secretory granules ( $g$ ). However, some cells (cell I in Fig. 10) display a relative intense labelling, while others (Fig.9) have intermediate intensities and others (cells II and III in Fig. 10) very low labelling. $L$, acinar lumen. Fig. $9: 24300$ Fig. 10: $\times 10000$ lowering of the blood glucose levels was closely related to the consumption of the vanadate and was rapidly reversible when the vanadate solution was replaced by tap water (Fig. 2). Indeed, when the vanadate treatment was replaced by water for a period of two days, the blood glucose levels of vanadate-treated diabetic animals (Group IV), rose drastically in less than $24 \mathrm{~h}$ (Fig.2). They fell again to low values as soon as the vanadate treatment was resumed (Fig. 2).

Insulin levels low in non-treated diabetic animals (Group III, $21.5 \pm 0.86 \mathrm{mU} / 1$ ) was even reduced with the vanadate treatment (Group IV, $16.8 \pm 1.2 \mathrm{mU} / 1$ ) (Table 1) $(p<0.001)$. On the other hand, vanadatetreated control animals (Group II) displayed insulin levels significantly lower $(28.1 \pm 1.8 \mathrm{mU} / \mathrm{l})$ than those of non-treated control animals (Group I, 44.78 \pm 2.9 $\mathrm{mU} / 1)($ Table 1$)(p<0.001)$.
Among the other blood factors analysed, the non-esterified fatty acid (NEFA) values while high in hyperglycaemic animals $(18.7 \pm 0.2 \mathrm{mmol}$ for Group III, vs $2.8 \pm 0.4 \mathrm{mmol}$ for the controls Group I, $p<0.001$ ), decreased with the vanadate treatment and the normalization of the blood glucose levels $(3.4 \pm 0.5 \mathrm{mmol}$ for the vanadate-treated diabetic animals, Group IV, vs $2.9 \pm 0.4 \mathrm{mmol}$ for the vanadate-treated control animals, Group I).

The immunofluorescence technique revealed insulin and glucagon cells in the islets of Langherans. In the control (Group D) as well as in the vanadate-treated control animals (Group II), the islets showed the classic architecture with a central large core formed by insulin secreting cells surrounded by a shell of glucagon secreting cells (Fig.3). In diabetic (Group III) as well as in vanadate-treated diabetic animals (Group IV), the num- 
ber of insulin secreting cells was fewer and the glucagon secreting cells appeared more numerous (Fig.4). No difference was detected between the vanadate-treated and the non-treated diabetic animals.

By electron microscopy, the insulin- and glucagonsecreting cells of the islets of Langerhans in vanadatetreated animals (diabetic and control) appear similar, with a large number of secretory granules. Similarly, the acinar parenchyma showed a normal morphology with the exception of the non-treated diabetic animals (Group II), in which the acinar cells displayed large accumulations of lipid droplets. This confirms observations reported previously [26]. These accumulations of lipids were significantly reduced in vanadate-treated diabetic animals (Group IV) with the normalization of the blood glucose levels.

Amylase content by the acinar cells as assessed by immunocytochemical and biochemical approaches was drastically decreased in non-treated diabetic animals (Group III) when compared to the controls (Group I) (Table 2). Indeed, application of the protein A-gold immunocytochemical technique on pancreatic tissue of non-treated control animals (Group I), yielded a labelling by gold particles over the acinar cells which was particularly intense over the cellular compartments involved in secretion (Fig. 5). The gold particles, revealing amylase antigenic sites, were present over the rough endoplasmic reticulum, the cisternae of the Golgi apparatus, the condensing vacuoles and the secretory zymogen granules (Fig. 5). The later being the most intensely labelled. Very few gold particles were present over mitochondria and nuclei (Fig.5). However, in non-treated diabetic animals (Group III), the labelling of amylase in the acinar cells was very sparse (Fig. 6). Few gold particles were present over the rough endoplasmic reticulum, Golgi apparatus and zymogen granules. These results, reflecting an inhibition in amylase secretion, were confirmed by the quantitative evaluation of the intensities of labelling and were found to be in agreement with the biochemical determination of amylase content in the pancreatic tissues (Table 2).

In vanadate-treated control animals (Group II), immunolabelling for amylase was present in all the cellular compartments involved in secretion; particularly the zymogen granules (Fig. 7). The quantitative results demonstrated that there was no difference in intensities of labelling between treated (Group II) and non-treated control animals (Group I) (Table 2). This was also confirmed by the biochemical determinations (Table 2). As stated previously, the vanadate-treated diabetic animals (Group IV) were divided into two subgroups depending on their response to the treatment. In the larger subgroup which demonstrated a stable normoglycaemic state, the labelling for amylase in acinar cells was present in significant amounts in all the cellular compartments involved in secretion; particularly in the zymogen granules (Fig. 8). The quantitative evaluation confirmed this fact and further demonstrated that the labelling in the zymogen gran- ules, was similar to that found in the non-treated control animals (Table 2). This was also supported by the biochemical analysis (Table 2). The second subgroup of vanadate-treated diabetic animals which demonstrated unstable values of blood glucose levels, displayed an intermediate situation concerning the labelling of amylase. Indeed, in most acinar cells the zymogen granules were labelled but to a lesser extent than in control animals (Figs. 9 and 10). In other cells, the granules were almost devoid of labelling, demonstrating a lack of amylase (Fig. 10). The fact that the amounts of amylase in the pancreas of these animals was intermediate between those from the normal and the diabetic animals was confirmed by the biochemical determinations (Table 2 ).

The experiments performed in order to assess the validity of the immunolabelling confirmed its specificity. Indeed, addition of the antigen to the antibody or omission of the antibody, resulted in an absence of labelling, as also reported previously [15, 20, 21] (results not shown).

\section{Discussion}

In the present study we have demonstrated that oral administration of sodium metavanadate to streptozotocininduced diabetic rats leads to normalization of their blood glucose levels. We have found that the decrease in glucose level occurs only when the concentration of vanadate reaches $0.8 \mathrm{mg} / \mathrm{ml}$. With lower concentrations, the response was not stable and blood glucose levels remained high. Furthermore, it was also found that by gradually increasing the concentration, the animals were more receptive to the vanadate treatment. The animals responded however, with differing sensitivities. The group of streptozotocin-diabetic vanadate-treated rats (Group IV) was separated into two subgroups according to their response. The first which comprised the majority of the animals, maintained a stable normoglycaemic state while in the second subgroup the animals displayed inconsistent glycaemic values which varied from one day to another. On the other hand, the lowering of the blood glucose level was closely related to the vanadate consumption. Indeed, the effect was reversible and the hyperglycaemic state recurred as soon as the treatment was ceased. The lowering of the blood glucose levels may be due to stimulation of glucose uptake, glucose oxidation and glycogen synthesis elicited by the presence of high levels of circulating vanadium [3]. The levels of circulating insulin remained low in the vanadate-treated diabetic animals which indicates that the lowering of glycaemic values was probably due to the insulin mimetic effect of vanadate inducing changes in glucose metabolism [1-8]. Vanadate-treated control animals displayed low levels of insulin. These results seem to indicate that vanadate treatment, by stimulating glucose uptake and metabolism, mimic the action of insulin and consequently may reduce its secretion. 
No major modifications due to vanadate treatment, were detected by a morphological approach in the endocrine cells of the islets of Langerhans. However, the accumulation of lipid droplets found in the acinar cells of non-treated diabetic animals, previously reported as being of cholesterol nature [25], were reduced after vanadate treatment. This may be due to the lowering of blood glucose levels and stimulation of glucose utilization. Further, the levels of circulating NEFA were also restored with the lowering of the glucose levels by vanadate. These may be related to the reported action of vanadate in stimulating glucose incorporation into lipids in adipocytes and increase in hepatic glycogenesis [1, 8]. The results obtained for amylase in the pancreas appear also to parallel the glycaemic response to the vanadate treatment. Indeed those animals which became normoglycaemic had their levels of pancreatic amylase normalized to values equivalent to those of the control animals. On the other hand, the vanadate treated animals with inconsistent glycaemia showed intermediate amylase values. It has been previously demonstrated that amylase secretion by acinar cells in hyperglycaemic conditions is restored by insulin treatment $[15,17]$. However, it is difficult from these experiments, to discriminate between the roles played by glucose from those of insulin. From the results obtained in the present study we can better discriminate between the two factors since restoration of amylase secretion does occur in conditions of low glucose and low insulin levels. Furthermore, fluctuations of glucose levels with low insulin, resulted in an intermediate response from the acinar cells. These results thus tend to support the hypothesis that amylase secretion by acinar cells is related to glucose metabolism rather than to the direct action of circulating insulin.

Acknowledgments. We thank Drs. E. Rasio and E. Levy for their help in the evaluation of the sera. This investigation was supported by grant MT-7284 from the Medical Research Council of Canada. M. Bendayan is recipient of a Scientist Award from the MRC.

\section{References}

1. Gil J, Miralpeix M, Carreras J, Bartrons R (1988) Insulin-like effects of vanadate on glucokinase activity and fructose 2,6-bisphosphate levels in the liver of diabetic rats. J Biol Chem 263: 1868-1971

2. Heyliger CE, Tahiliani AG, McNeil JH (1985) Effect of vanadate on elevated blood glucose and depressed cardiac performance of diabetic rats. Science 227: 1474-1477

3. Meyerovitch J, Farfel Z, Sack J, Shechter Y (1987) Oral administration of vanadate normalizes blood glucose levels in streptozotocin-treated rats. Characterization and mode of action. $\mathrm{J}$ Biol Chem 262: 6658-6662

4. Degani H, Gochin M, Karlish SJD, Shechter Y (1981) Electron paramagnetic resonance studies and insulin-like effects of vanadium in rat adipocytes. Biochem 20:5795-5799

5. Dubyak GR, Kleinzeller A (1980) the insulin-mimetic effects of vanadate in isolated rat adipocytes. Dissociation from effects of vanadate as a $\left(\mathrm{Na}^{+}-\mathrm{K}^{+}\right)$ATPase inhibitor. $\mathbf{J}$ Biol Chem 255: $5306-5312$
6. Duckworth WC, Solomon SS, Liepnieks J, Hamel FG, Hand S, Peavy DE (1988) Insulin-like effects of vanadate in isolated rat adipocytes. Endocrinol 122: 2285-2289

7. Shechter Y, Karlish SJD (1980) Insulin-like stimulation of glucose oxidation in rat adipocytes by vanadyl (IV) ions. Nature 284: $556-558$

8. Tamura S, Brown TA, Whipple JH, Fujita-Yamaguchi Y, Dubler RE, Cheng K, Larner J (1984) A novel mechanism for the insulinlike effect of vanadate on glycogen synthase in rat adipocytes. $\mathrm{J}$ Biol Chem 259: 6650-665i8

9. Hori C, Oka T (1980) Vanadate enhances the stimulatory action of insulin on DNA synthesis in cultured mouse mammary gland. Biochim Biophys Acta 610: 235-240

10. Fagin JA, Ikejiri K, Levin SR (1987) Insulinotropic effects of vanadate. Diabetes 36: 1448-1452

11. Bendayan M (1982) Cell contacts between endocrine and exocrine cells in the pancreas. Cell Tiss Res 222: 227-230

12. Bendayan M (1985) Morphometrical and immunocytochemical characterization of peri-insular and tele-insular acinar cells in the rat pancreas. Eur J Cell Biol 36: 263-268

13. Bendayan $M$ (1987) Presence of endocrine cells in pancreatic ducts. Pancreas 2: 393-397

14. Bendayan M, Grégoire S (1987) Immunohisto-and cytochemical studies of pancreatic enzymes in peri-insular and tele-insular acinar cells of streptozotocin-induced diabetic rats. Pancreas 2: 272-282

15. Grégoire S, Bendayan M (1986) Immunocytochemical studies of pancreatic acinar cells in normal and streptozotocin-induced diabetic rats. Diabetologia 29: 655-660

16. Korc M, Owerbach D, Quinto C, Rutter WJ (1981) Pancreatic islet-acinar cell interaction: amylase messenger RNA levels are determined by insulin. Science 213: 351-353

17. Williams JA, Goldfine ID (1985) The insulin-pancreatic acinar axis. Diabetes 34: 980-986

18. Grégoire S, Bendayan M (1987) Immunocytochemical studies of pancreatic acinar cells in spontaneously diabetic BB rats. Pancreas 2: 205-211

19. Bendayan M, Levy E (1988) Immunocytochemical and biochemical evaluation of pancreatic lipase in acinar cells of control and streptozotocin-induced diabetic rats. Pancreas 3: 269-273

20. Bendayan M, Ito S (1979) Immunohistochemical localization of exocrine enzymes in normal rat pancreas. J Histochem Cytochem 27: 1029-1034

21. Bendayan M (1984) Protein A-gold electron microscopic immunocytochemistry: methods, applications and limitations. J Electron Microsc Tech 1: 243-270

22. Mongeau R, Couture Y, Dunnigan J, Morisset J (1974) Early dissociation of protein synthesis and amylase secretion following hormonal stimulation of the pancreas. Can J Physiol Pharmacol 52: 198-205

23. Ceska M, Birath K, Brown B (1969) A new and rapid method for the clinical determination of $\alpha$-amylase activities in human serum and urine. Optimal conditions. Clin Chim Acta 26: 437-444

24. Lowry OH, Rosenbrough NJ, Farr AL, Randall RJ (1951) Protein measurement with Folin-phenol reagent. J Biol Chem 193: 265-275

25. Levy E, Roy CC, Lepage G, Bendayan M (1988) Lipid abnormalities in pancreatic tissue of streptozotocin-induced diabetic rats. Lipids 23: 771-778

Received: 28 November 1988

and in revised form: 19 April 1989

Dr. M. Bendayan

Department of Anatomy

Universite de Montreal

C.P. 6128 Succ. A

Montreal, Quebec, H3C 3J7

Canada 